\title{
The use of algorithms to predict surface seawater dimethyl sulphide concentrations in the SE Pacific, a region of steep gradients in primary productivity, biomass and mixed layer depth
}

\author{
A. J. Hind ${ }^{1}$, C. D. Rauschenberg ${ }^{1}$, J. E. Johnson ${ }^{3}$, M. Yang $^{2}$, and P. A. Matrai ${ }^{1}$ \\ ${ }^{1}$ Bigelow Laboratory for Ocean Sciences, 180 McKown Point Road, West Boothbay Harbor, ME 04575-475, USA \\ ${ }^{2}$ Department of Oceanography, University of Hawaii, Honolulu, HI, USA \\ ${ }^{3}$ Pacific Marine Environmental Laboratory, NOAA, Seattle, Washington, USA
}

Received: 26 April 2010 - Published in Biogeosciences Discuss.: 13 July 2010

Revised: 17 November 2010 - Accepted: 14 December 2010 - Published: 3 January 2011

\begin{abstract}
Dimethyl sulphide (DMS) is an important precursor of cloud condensation nuclei (CCN), particularly in the remote marine atmosphere. The SE Pacific is consistently covered with a persistent stratocumulus layer that increases the albedo over this large area. It is not certain whether the source of CCN to these clouds is natural and oceanic or anthropogenic and terrestrial. This unknown currently limits our ability to reliably model either the cloud behaviour or the oceanic heat budget of the region. In order to better constrain the marine source of CCN, it is necessary to have an improved understanding of the sea-air flux of DMS. Of the factors that govern the magnitude of this flux, the greatest unknown is the surface seawater DMS concentration. In the study area, there is a paucity of such data, although previous measurements suggest that the concentration can be substantially variable. In order to overcome such data scarcity, a number of climatologies and algorithms have been devised in the last decade to predict seawater DMS. Here we test some of these in the SE Pacific by comparing predictions with measurements of surface seawater made during the Vamos Ocean-Cloud-Atmosphere-Land Study Regional Experiment (VOCALS-REx) in October and November of 2008. We conclude that none of the existing algorithms reproduce local variability in seawater DMS in this region very well. From these findings, we recommend the best algorithm choice for the SE Pacific and suggest lines of investigation for future work.
\end{abstract}

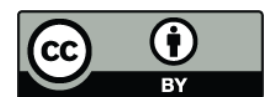

Correspondence to: A. J. Hind

(ajhind@googlemail.com)

\section{Introduction}

\subsection{Clouds in the SE Pacific and DMS}

In clean marine air the supply of cloud condensation nuclei $(\mathrm{CCN})$ is often limiting, particularly in the Southern Hemisphere, yet in the southeast Pacific there is abundant cloud cover. As little rain falls here, CCN may be long lived, not being removed in precipitation. However, "pockets of open cells" (POCs) periodically form, probably the result of a light drizzle falling, and so a break in the cloud cover is formed (Bretherton et al., 2004). The trigger for this precipitation is unknown; it may relate to the availability of CCN (Stevens et al., 2005). This hole may take several days to close up and the mechanism of refilling is uncertain (Bretherton et al., 2004). Dimethyl sulphide (DMS) is continually emitted from the ocean at all latitudes and is the principal natural source of sulphur to the atmosphere (Bates et al., 1992). Once in the air, a portion is oxidised to acidic aerosols which may act as CCN. Indeed, in the marine boundary layer, oxidised DMS is thought to be the principal source of CCN (Charlson et al., 1987), although the role of other substances, including gels (Bigg and Leck, 2001) and sea salt aerosol (O'Dowd et al., 1997), is not well known. The SE Pacific region suffers from scant spatial and temporal coverage of seawater DMS measurements (unless otherwise stated, all references to DMS concentrations refer to that of seawater). In the limited data, there are glimpses of variability; for example, against measured average DMS values of $\sim 2.5 \mathrm{nM}$, there were hot spots of higher DMS concentrations $(\sim 5.5 \mathrm{nM})$ observed during two cruises in the region in October 2006 and October/November 2007 (B. Huebert, U. Hawaii, personal communication, 2009). The cause of these elevated values is not clear, but they may result from higher light or UV levels

Published by Copernicus Publications on behalf of the European Geosciences Union. 
A. J. Hind et al.: The use of algorithms to predict surface seawater dimethyl sulphide concentrations

during a POC, or were associated with a front that enhanced nutrient availability, or affected the depth of the mixed layer, all leading to enhanced biological production or release of DMS in the environment (Stefels et al., 2007). Much higher DMS concentrations, exceeding $40 \mathrm{nM}$, have been reported in the coastal waters of the Peruvian upwelling, with the maxima observed within $10 \mathrm{~km}$ of the shore, accompanied by elevated levels of phytoplankton biomass (Andreae, 1985).

\subsection{Causes of seawater DMS variability}

The flux of DMS to the atmosphere is ultimately driven by the seawater concentration which is regulated by complex processes, with both the sources and sinks being variable. The uncertainties in seawater DMS concentrations are larger than those in the gas transfer coefficient (Nightingale et al., 2000) so, in order to improve our estimates of the flux to the atmosphere, an improved knowledge of the seawater concentrations is necessary. Different groups of phytoplankton produce differing amounts of DMS (Keller et al., 1989) such that simple correlations with chlorophyll or biomass do not work well over large scales (Kettle et al., 1999). At lower latitudes, there is usually a succession of phytoplankton types following winter mixing, from low DMS producers (diatoms) to higher producers (haptophytes) while both chlorophyll and biomass decline (Simó and Pedros-Alio, 1999). Paradoxically, the highest DMS concentrations may occur when the chlorophyll concentration is at its lowest, for example in the Sargasso Sea (Dacey et al., 1998; Toole et al., 2003).

DMSP is the precursor to DMS. DMS and acrylate (and a proton) are produced from DMSP via enzymatic cleavage (Stefels and van Boekel, 1993). DMSP is known to be made by a range of micro and macroalgae as well as by a few higher plants (Stefels, 2000), yet the functions of DMSP and its metabolites may be numerous and remain controversial. It has been suggested to function as an osmolyte (Kirst, 1996), a cryoprotectant (Karsten et al., 1996), a grazing deterrent (Wolfe et al., 1997; Steinke et al., 2002), as a viral defence (Evans et al., 2006), and as an antioxidant (Sunda et al., 2002), amongst other roles. It should be noted that while phytoplankton are the main source of DMSP, recent advances in understanding the DMS cycle indicate that it is the entire marine planktonic food web that determines net DMS production along with photochemical and photobiological processes. Only a small fraction (1-2\%) of the DMSP will enter the atmosphere as DMS due to the interactions of the physics, chemistry and biology in surface ocean waters (Kiene and Linn, 2000; Bates et al., 1994).

Some data show that the DMS flux to the atmosphere correlates with solar irradiation (Bates et al., 1987), yet in such conditions the photodestruction of DMS in both the atmosphere and the ocean is probably elevated. Over the Southern Ocean, under high UV conditions, atmospheric DMS is observed to decline (Kniveton et al., 2005), although the opposite can be true; in seawater, the DMS concentration may increase with irradiation, despite elevated photodestruction (Toole et al., 2003).

\subsection{Approaches to predicting seawater DMS concentrations}

\subsubsection{Specific algorithms}

We do not have a reliable global climatology for DMS despite extensive ocean exploration and sophisticated remote sensing. DMS production and loss processes are complex and the path from the cell to the atmosphere is tortuous. DMS measurements are still comparatively low in number compared to other dissolved gases and there are few automated instruments enabling high resolution measurements to be made. A slew of predictive methods and algorithms has been generated in a order to better understand DMS processes and provide accurate estimates of seawater DMS concentrations. Some of the more recent ones shall be considered here. For clarity we use abbreviations to identify them. Kettle et al. (1999), Kettle and Andreae (2000), Anderson et al. (2001), Aumont et al. (2002), Simó and Dachs (2002), Chu et al. (2003), Aranami and Tsunogai (2004), Belviso et al. (2004b), Vallina and Simó (2007) and Miles et al. (2009) will be referred to as $\mathrm{K} 99, \mathrm{~K} 00$, AN01, AU02, SD02, $\mathrm{CH} 03$, AT04, BE04, VS07 and MI09, respectively.

A significant step in the study of DMS was the production of the global, monthly $1^{\circ} \times 1^{\circ}$ climatologies K99 and K00. K00 was a development of K99 where new data were added and problem areas addressed. Ultimately the difference between the two sets is small excepting at the high latitudes. The global dataset encouraged modelling work and the development of algorithms and they are still a key standard to which parameterisations are shaped and tested. Algorithms AU02, SD02, and $\mathrm{CH} 03$ were determined using K99 whilst AN01, BE04 and AT04 used K00. The data that the Kettle climatologies were based on, along with newer measurements, can be found in the global DMS database (http://saga.pmel.noaa.gov/dms/).

The process model AU02 used chlorophyll $a$ (hereafter chlorophyll) and a measure of the phytoplankton community composition, the Fp, to estimate DMSP-particulate (DMSPp) and DMS concentrations with formulations derived from field data. Fp is determined from measured pigment concentrations (Claustre, 1994). As field measurements of Fp are scarce, AU02 estimates the values by applying better understood silicate-related modelling. Put simply: if silica driven production is high, diatoms (which typically produce little DMS/P) are abundant, so the Fp ratio will also be high. Thus, at a high Fp, the DMSP:Chlorophyll ratio will be correspondingly low (Aumont et al., 2002). The model works quite well but does not reproduce high latitude, high DMS/P Phaeocystis blooms and runs into problems in high nutrient, low chlorophyll (HNLC) regions as well, as it does not account for limitation of productivity resulting from low silicate or 
iron as is known to occur, for example, in the Equatorial Pacific.

BE04 is a modification of the AU02 relationship in which the authors estimate Fp from chlorophyll concentration alone, employing an empirical relationship that was determined over a number of field studies at various latitudes. A drawback of this method is, perhaps unsurprisingly, that the parameterisation leads to DMS concentration being too closely correlated with chlorophyll (Belviso et al., 2004a). More generally BE04 underestimated seawater DMS. Firstly, the authors found it did not reproduce the high DMS encountered on a summer Indian Ocean cruise, and so it is suggested that this may have resulted from sampling at the end of a phytoplankton bloom, where cell contents were released into the surrounding water leading to lysis of DMSP to DMS. Secondly, when dinoflagellates were suspected to be abundant, once more a relatively high DMS:DMSP ratio occurs, so DMS is underestimated despite the estimate of the DMSP concentration being good.

Like AU02, CH03 has a strong biological basis; a mechanistic DMS component was added to a biogeochemical ocean model. Ultimately, mechanistic models are desirable as a good understanding of the involved processes is needed, and this can provide a stronger basis for prediction than observed correlation. The $\mathrm{CH} 03$ model results correlate fairly well with measured chlorophyll and most of the natural features are reproduced, except in upwelling areas and coastal waters. Despite this, the seawater DMS concentrations have a large bias and do not reproduce observed seasonality (Belviso et al., 2004a).

The AN01 model was produced to predict surface seawater DMS concentrations from chlorophyll, irradiance, and a nitrate limitation term. Anderson et al. (2001) determined the values for the coefficients in the equations by fitting data from K99 to SeaWiFS chlorophyll data and to light fields, which were then applied seasonally to a global annual nitrate climatology. The calculated estimator increases with increases in chlorophyll, irradiance, or nitrate. However, large regions of the surface ocean of the tropics and subtropics have low nutrients and chlorophyll; these places are deemed likely to have low seawater DMS concentrations, so are assigned a prescribed, fixed value of $2.29 \mathrm{nM}$, resulting in a two part relationship. Consequently the variability in such zones is lost. Belviso et al. (2004b) noted half the DMS values in K00 were below this concentration and hence AN01 is not applicable.

Like AN01, SD02 and AT04 also use a two-part, or "broken stick", relationship, recognising that in oligotrophic regions the DMS concentration can vary dramatically without a consistent relationship to chlorophyll. Unlike AN01, these algorithms used mixed layer depth (MLD) as a variable, recognising its apparent relation to DMS as observed by Simó and Pedros-Alio (1999). They are more sophisticated than AN01 in that, rather than applying a constant value when low values are expected, a different relationship is used to better reflect these conditions. The SD02 formulation began with the K99 dataset from which the highest DMS and chlorophyll measurements were removed. In these data, two relationships were found using the proxies productivity, as estimated from the chlorophyll concentration, and the MLD although at low chlorophyll the estimation is made from the MLD alone. The authors drew on a previous observation that in regions where chlorophyll is always quite low, less than $0.5 \mu \mathrm{g} 1^{-1}$, there is a negative correlation between MLD, chlorophyll, and DMS (Simó and Pedros-Alio, 1999). Contrastingly, in more eutrophic regions, there is a positive relationship between chlorophyll and DMS. MLD was defined as the depth at which the density was $0.125 \mathrm{~kg} \mathrm{~m}^{-3}$ higher than at the surface. They proposed that below a constant value for the ratio of chlorophyll divided by MLD (C/MLD), DMS was constant per area and that the variation in concentration was driven by the relative dilution caused by changes in the MLD.

AT04 is a refinement of SD02. The authors found that in the more productive waters, the SD02 relationship was adequate, but that in less productive waters, DMS was effectively constant by area so the change in concentration was caused by dilution effects alone, such that a doubling of the MLD results in a halving of the DMS concentration.

The newest predictive approach has been the use of a linear relationship between DMS and a "solar radiation dose" (SRD), as proposed by Vallina and Simó (2007). SRD was determined from MLD and short wave irradiance and thus dispenses with the need for chlorophyll, Fp, or nutrient measurements. It is attractive as the influence of solar radiation has been indicated (Bates et al., 1987; Toole and Siegel, 2004) and it requires only frequently collected data, unlike AU02. MI09 was a modification of VS07, where a strong correlation was found between an ultraviolet A radiation dose (UVRD) and DMS. MI09 used the dataset of Bell et al. (2006), collected during the Atlantic Meridional Transect (AMT) cruises, mostly in oligotrophic waters. As some studies have found that phytoplankton demonstrate a particular sensitivity to UV, MI09 seems plausible. For example, under elevated UV, some species produce more DMS (Sunda et al., 2002). Additionally DMSP to DMS conversion can increase (Hefu and Kirst, 1997) and bacterioplankton activity is suppressed (Herndl et al., 1993), reducing DMS and DMSP consumption. VS07 found linear relations between SRD and the monthly mean DMS concentrations at two time series stations and over the global ocean.

\subsubsection{Comparison of algorithms}

Comparisons of the climatologies and algorithms have already been made. Belviso et al. (2004a) assessed the Kettle databases and the algorithms AN01, AU02, SD02, $\mathrm{CH} 03$, and BE04, and found substantial discrepancies between the predicted concentrations. Both AN01 and BE04 were identified as having little variability in DMS over 
large ocean tracts, although the latter predicted a value for such regions of about half that predicted by the former. Indeed, when Belviso et al. (2004a) were comparing all the models and the Kettle climatologies with the raw data that they were constructed from, the global DMS database (http://saga.pmel.noaa.gov/dms/), a bias was found in each. Four underestimated the measured concentrations and two overestimated them. K99 and K00 underestimated by 0.36 and $0.33 \mathrm{nM}$, respectively. Globally, AN01 was found to be the best overall with an overestimation of seawater DMS of only $0.16 \mathrm{nM}$, while $\mathrm{CH} 03$ underestimated the concentration by $1.47 \mathrm{nM}$. AU02 performed only slightly better, given that the mean underestimation of the measured global value was $1.38 \mathrm{nM}$. Summarising, SD02 and CH03 were deemed to be best in the equatorial Pacific as they reproduced the observed seasonal changes. AN01 predictions were a good fit to the annual mean concentrations but did not resolve either the spatial or seasonal variation at lower latitudes. They found that no model performed well in the North Pacific. A comparison approach like this cannot be used to test the performance of the models and climatologies in the SE Pacific, as there are so few measurements in the DMS database for that region.

Bell et al. (2006) also reviewed the performance of the databases K99 and $\mathrm{K} 00$ and the algorithms AN01, AU02, BE04, SD02, and AT04 and compared the estimate from each with their AMT dataset. Their list, ranked from worst to best was: AT04 (when using a constant optimised to their dataset), AU02, SD02, BE04, and AN01. In the cases of SD02, AT04, AN01 and BE04, most or all of the Bell et al. (2006) sampling stations fitted into the low productivity part of the two part relationships. In the case of application of AN01 to the AMT data, a constant value was estimated for every station over five cruises and this was too high in $92 \%$ of cases (Bell et al., 2006).

More recently, Miles et al. (2009) compared the Bell et al. (2006) data with the predictions made by VS07 and by their development of the MI09 relationship. They found that by using VS07 or MI09 to estimate AMT DMS, the results were comparably robust to values estimated using the AT04 relationship optimised by Bell et al. (2006). MI09 determined the SRD in their study using a MLD climatology and calculated irradiance (which does not account for variability caused by clouds). Interestingly, the relationship was found to be weaker if calculated using in situ measurements of either MLD or irradiance.

Since Bell et al. (2006), Belviso and Caniaux (2009) reviewed the VS07 method using data from the NE Atlantic and did not find as strong a relationship between SRD and DMS as was found in the NW Atlantic, specifically the Sargasso Sea. Additionally, Derevianko et al. (2009) criticized the VS07 binning procedure, as it artificially strengthened the SRD and DMS relationship. Miles et al. (2009) disputed the conclusions of the Belviso and Caniaux (2009) study and cited an incorrect use of statistics, leading to an underesti- mation of the strength of the relationship; the same criticism would stand against the Derevianko et al. (2009) paper. However, this issue alone does not explain the poor performance of the VS07 approach in these later studies.

\subsection{Aims}

The SE Pacific is poorly sampled and published seawater DMS data are limited to just a handful of measurements. An improved knowledge of the flux of DMS from the ocean to the atmosphere is needed to better describe the cloud processes that regulate the most persistent stratocumulus deck in the world (Bretherton et al., 2004; Serpetzoglou et al., 2008). These clouds have a high albedo that exerts a significant cooling that influences the heat budget over a substantial region of the Pacific Ocean (Cronin et al., 2006). Occasionally, small breaks open rapidly, which allow more incoming radiation to reach the surface ocean likely affecting surface ocean biogeochemical processes. These holes take several days to close and the closure is probably the result of $\mathrm{CCN}$ of marine biogenic origin, particularly at locations far from the coast. DMS is very likely an important sulphur source to the atmosphere in the region, some of which will become CCN. Herein, we use high resolution seawater DMS and mixed layer depth measurements to test the suitability of available DMS predictive algorithms for use in the SE Pacific and judge the reliability of the published DMS climatologies within the region. This provides a unique opportunity to test all of these predictive algorithms with a single dataset, encompassing a wide range of contrasting hydrographic conditions ranging from open ocean oligotrophic gyre to eutrophic upwelling near the coast. The algorithms examined in this work are AN01, SD02, AT04, BE04, VS07 and MI09. AU02 was not tested as the supporting measurements to determine Fp were not made. $\mathrm{CHO3}$ is not explored here as it is a complex process model, instead of a parameterisation which can be applied to the measured or climatological data, and is thus outside of the scope of this work.

\section{Methods}

\subsection{Collection of in situ data}

Measurements were made on the VOCALS (VAMOS OceanCloud-Atmosphere-Land Study; VAMOS - Variability of the American MOnsoon Systems, information at http://www. clivar.org/organization/vamos/vamos.php) Stratus 9 cruise, as part of the VOCALS Regional Experiment (REx, information at http://www.eol.ucar.edu/projects/vocals/) on the NOAA research vessel Ronald $H$. Brown. The first leg was from Charleston, SC, USA to Arica, Chile (29 September3rd November 2008) and the second from Arica to $\sim 20^{\circ} \mathrm{S}$, $85^{\circ} \mathrm{W}$, returning to Arica (9 November-2 December 2008).

DMS in seawater was either discretely or semicontinuously sampled and determined according to the 
methods of Matrai and Keller (1993) and Bates et al. (2000), respectively. The discrete samples were either taken from Niskin bottles on the CTD rosette closed at depths less than $10 \mathrm{~m}$ or from the ship's non-toxic supply fed from an inlet at approximately $5 \mathrm{~m}$ below the sea surface. The semicontinuous instrument sampled water from the ship's nontoxic supply approximately every $30 \mathrm{~min}$. Both systems are based on a "purge and trap" GC-FPD design. They differed only in that the discrete instrument was calibrated using liquid DMS standards whilst the semi-continuous instrument employed gravimetrically calibrated DMS and MES permeation tubes.

Chlorophyll fluorescence was measured continuously in water taken from the ship's non-toxic supply using a 10AU fluorometer fitted with a flow through cell (Turner Designs, Sunnyvale, CA). Discrete samples were taken in triplicate at least twice daily and used to calibrate the continuous instrument. The samples were filtered onto $25 \mathrm{~mm}$ filters (GF/F, Whatman Ltd., Kent, UK) and immediately frozen at $-20^{\circ} \mathrm{C}$ for subsequent analysis according to Holm-Hansen et al. (1965). These were measured with a second 10AU fluorometer fitted with a discrete sample cell and calibrated using pure chlorophyll a (Sigma Biochemicals).

Measurements of temperature and salinity were made on station using a Sea-Bird 911-plus CTD/rosette, augmented with data from 425 deployments of a towed Oceanscience underway CTD system (Oceanscience, Oceanside, California) which contained a Sea-Bird CTD probe 10-400. These data were used to determine the in situ MLD. This is defined as the depth at which there is a $0.1^{\circ} \mathrm{C}$ departure from the temperature at $10 \mathrm{~m}$ below the surface. This removes the influence of shallow, short lived, surface stratification. As DMS data were collected throughout the day and night, it was particularly important to use a definition which removed this diurnal variability and reflected the depth of the mixed layer the majority of the time. The resultant data were high resolution but, in order to provide MLD data to correspond with the positions where seawater DMS was measured, a weighted average method was used to interpolate between points (Schlitzer, R., Ocean Data View, http://odv.awi.de, 2010).

Samples collected for nitrate concentration determination were taken from either the CTD rosette or from the ship's non-toxic supply and frozen at $-20^{\circ} \mathrm{C}$ for analysis using standard techniques (Parsons et al., 1984) by the MSI Nutrient Lab at the Marine Science Institute, UC Santa Barbara. To correspond with DMS sample points between nitrate samples, the weighted average method was also used.

Incoming short wave (SW) radiation $(300-3000 \mathrm{~nm})$ was obtained from two Eppley PSP units. For each sampling time, the mean incoming radiation over the preceding 24 hours was determined. These were mounted on platforms that corrected for the motion of the ship. The UV wavelength range of 355-399 nm was measured using a Satlantic HyperOCR hyperspectral radiometer (Satlantic Inc, Nova Scotia,
Canada). Data were binned into $5 \mathrm{~nm}$ wide bands and averaged hourly. As an in situ equivalent to the Total Ozone Mapping Spectrometer (TOMS) UV data used by MI09 we used the hourly value over solar noon from the 380-384 nm data band. Although these measurements are similar, they are not interchangeable.

\subsection{Algorithms application methods}

For use with the AN01 and BE04 algorithms, SeaWiFS chlorophyll data for the study period were downloaded from the NASA/GSFC/DAAC webpage (http://oceancolor.gsfc.nasa.gov). The data selected were Level 3, averaged weekly at a $9 \mathrm{~km}$ resolution. In order to provide data to correspond with the positions where seawater DMS was measured, a weighted average method was used to interpolate spatially (Schlitzer, 2010) and a simple linear method was employed to interpolate temporally.

As for the SeaWiFS data, to retrieve DMS values from K99 and K00, a weighted mean method was used for each cruise sampling point to interpolate between the grid points for September, October, November, and December 2008 (Schlitzer, 2010). A weighted average was then applied temporally to interpolate to the sampling date.

For SD02, AT04, VS07, and MI09, the MLD data was required. In addition to the in situ MLD data, the climatologies of Monterey and Levitus (1997), hereafter ML97, and de Boyer Montegut et al. (2004), hereafter BM04, were used. ML97 uses a definition of a potential temperature change of $0.5^{\circ} \mathrm{C}$ from the surface (at the shallow depths considered here, the change in temperature caused by density change is negligible). BM04 uses a definition of a temperature change of $0.1^{\circ} \mathrm{C}$ from a depth of $5 \mathrm{~m}$, as used in VS07 and MI09.

For algorithms requiring irradiance, both in situ measured data and estimated values were used. The estimated values were calculated using the same method as used by Vallina and Simó (2007) and Miles et al. (2009). The top of atmosphere (TOA) solar irradiation was estimated using the equations of Brock (1981) with an atmospheric loss factor of 50\% applied. These data are referred to as TOA/2.

Unfortunately, NASA's Total Ozone Mapping Spectrometer (TOMS), used by MI09 to obtain a midday $380 \mathrm{~nm}$ UV surface irradiation, ceased operation in 2005 and data from the replacement instrument were not yet available in a gridded form. In its place, we used the NCAR Tropospheric Ultraviolet and Visible (TUV) Radiation Model (http://cprm.acd.ucar.edu/Models/TUV/; LeeTaylor and Madronich, 2007), which is based on the TOMS dataset and so is comparable to the data used by MI09.

\subsection{Assessment of algorithm performance}

The performance of each predictive method was assessed in three ways: the size of the mean residual $\left(\sqrt{\left(D M S_{\text {measured }}-\mathrm{DMS}_{\text {predicted }}\right)^{2}}\right)$, the strength of the 
Table 1. A summary of cruise data, firstly the mean, median and range of measured DMS, in situ chlorophyll, SeaWiFS chlorophyll irradiance, mixed layer depth (MLD) and UV and secondly, from calculations or climatologies, the mean, median and range of estimated irradiance (TOA/2), UV (TUV) and the MLD from the ML97 and BM04 climatologies.

\begin{tabular}{llcccc}
\hline Parameter & Units & Mean & Median & Max. & Min. \\
\hline DMS & $\mathrm{nM}$ & 2.9 & 2.6 & 14.1 & 1.0 \\
Chlorophyll in situ & $\mu \mathrm{g} \mathrm{l}-1$ & 0.43 & 0.26 & 8.23 & 0.01 \\
Chlorophyll SeaWiFS & $\mu \mathrm{g} \mathrm{l}^{-1}$ & 0.18 & 0.18 & 0.60 & 0.04 \\
Irradiance in situ & $\mathrm{W} \mathrm{m}^{-2}$ & 235 & 229 & 334 & 153 \\
MLD in situ & $\mathrm{m}_{\text {UV in situ }}$ & 70 & 61 & 145 & 16 \\
TOA/2 & $\mathrm{W} \mathrm{m}^{-2} \mathrm{~nm}^{-1}$ & 0.50 & 0.49 & 0.74 & 0.31 \\
TUV & $\mathrm{W} \mathrm{m}^{-2}$ & 220 & 222 & 230 & 208 \\
ML97 & $\mathrm{W} \mathrm{m}^{-2} \mathrm{~nm}^{-1}$ & 0.89 & 0.91 & 0.99 & 0.81 \\
BM04 & $\mathrm{m}$ & 52 & 50 & 98 & 7 \\
\hline
\end{tabular}

correlation coefficient $\left(r^{2}\right)$, and the Spearman's rank correlation coefficient $(\rho)$. None is an ideal statistic. As the data were not normally distributed, $r^{2}$ is not entirely appropriate; however, it is used elsewhere (e.g. Belviso and Caniaux, 2009; Vallina and Simó, 2007; Belviso et al., 2004a) and is thus useful to include for comparison. Spearman's considers only the similarity between the order or rank of the $\mathrm{x}$ and $\mathrm{y}$ and data, not their absolute magnitude (used by Miles et al., 2009; Vallina and Simó, 2007). In this paper, all quoted $\rho$ values are significant to $<0.01$ unless otherwise stated. Finally, the mean residual may not show how well the relationship accounts for variability. A similar statistic, the median modulus, was used by Bell et al. (2006). Thus, by using all three assessments an overall performance rank can be generated.

\section{Results and discussion}

After leaving Panama, the R/V Ronald H. Brown sailed southwest to $\sim 8^{\circ} \mathrm{S}$, beginning a southerly transect along $\sim 85^{\circ} \mathrm{W}$ until $\sim 20^{\circ} \mathrm{S}$; thereon the ship followed longitudinal transects to survey mesoscale features and to service moorings. The cruise track is shown in Fig. 1, Panel A overlain on a plot of the mean sea surface height (SSH) anomaly for the first week of October 2008 (data downloaded from the AVISO website, www.aviso.oceanobs.com). Panels B and C of Fig. 1 contain plots of the in situ chlorophyll and DMS data, respectively. Data reported in this paper begin along the $85^{\circ} \mathrm{W}$ transect at $\sim 11.5^{\circ} \mathrm{S}$ on 23 October 2008 . Unless otherwise stated, the data described or plotted are in situ values or are derived from them. Figure 2 contains three frequency plots showing the distribution of the concentrations of DMS (Panel A), chlorophyll (Panel B), and the depth of mixed layer (Panel C). The chlorophyll concentrations were mostly low and typical of oligotrophic gyre conditions: $75 \%$ of DMS sampling locations have a concentration of $<0.5 \mu \mathrm{g}$ of chlorophyll $1^{-1}$ and $93 \%$ of $<1.0 \mu \mathrm{g}$ chlorophyll $\mathrm{l}^{-1}$. The DMS concentrations ranged from 1.0 to $14.1 \mathrm{nM}$, but the data were strongly skewed to the lower end of the range; the median and mean were $2.5 \mathrm{nM}$ and the mean was $2.9 \mathrm{nM}$, respectively. Most (92\%) of the DMS measurements were between 1.0 and $4.5 \mathrm{nM}$, with $43 \%$ being less than $2.3 \mathrm{nM}$. The median MLD was $61 \mathrm{~m}$ but varied between 16 and $145 \mathrm{~m}$. A summary of these data is given in the first section of Table 1 . Direct measurements of the sea-air flux of DMS during this cruise are reported elsewhere (Yang et al., 2009).

\subsection{Oceanographic biomes}

Given that DMS is biogenically produced in ocean waters, it is useful to consider the ecological biomes traversed during the 2008 VOCALS REx cruise. In terms of Longhurst's biogeochemical provinces, the initial section of the cruise was located within the Pacific Equatorial Divergence (PEQD), and the parts within $\sim 230 \mathrm{~km}$ of the coast were within the Humboldt Current Coastal Province (HUMB). The remainder, $89 \%$ of the sampling points, were within the South Pacific Subtropical Gyre (SPSG) (Longhurst, 1995). The characteristic, but general, features of each province provide some context and confidence to this one time sampling.

\subsubsection{The Pacific Equatorial Divergence (PEQD)}

The first section, from $11.5-15.5^{\circ} \mathrm{S}$, is within the PEQD province (Fig. 1, Panel A). MLD was $\sim 50 \mathrm{~m}$ in the northern part, $11.5-13.5^{\circ} \mathrm{S}$, from where it steadily deepened to $\sim 120 \mathrm{~m}$ by $15.5^{\circ} \mathrm{S}$. Chlorophyll was quite variable until $13.5^{\circ} \mathrm{S}$, between $0.07-0.35 \mu \mathrm{g} 1^{-1}$ whereafter it increased steadily as the MLD increased; by $15.5^{\circ} \mathrm{S}$, it was $\sim 0.5 \mu \mathrm{g} 1^{-1}$. The mean chlorophyll concentration in this province was $0.22 \mu \mathrm{gl}^{-1}$, the same as the SeaWiFS mean for the province for October/November 1997-2001 (Longhurst, 2007). PEQD is described as a high nutrient, low chlorophyll 


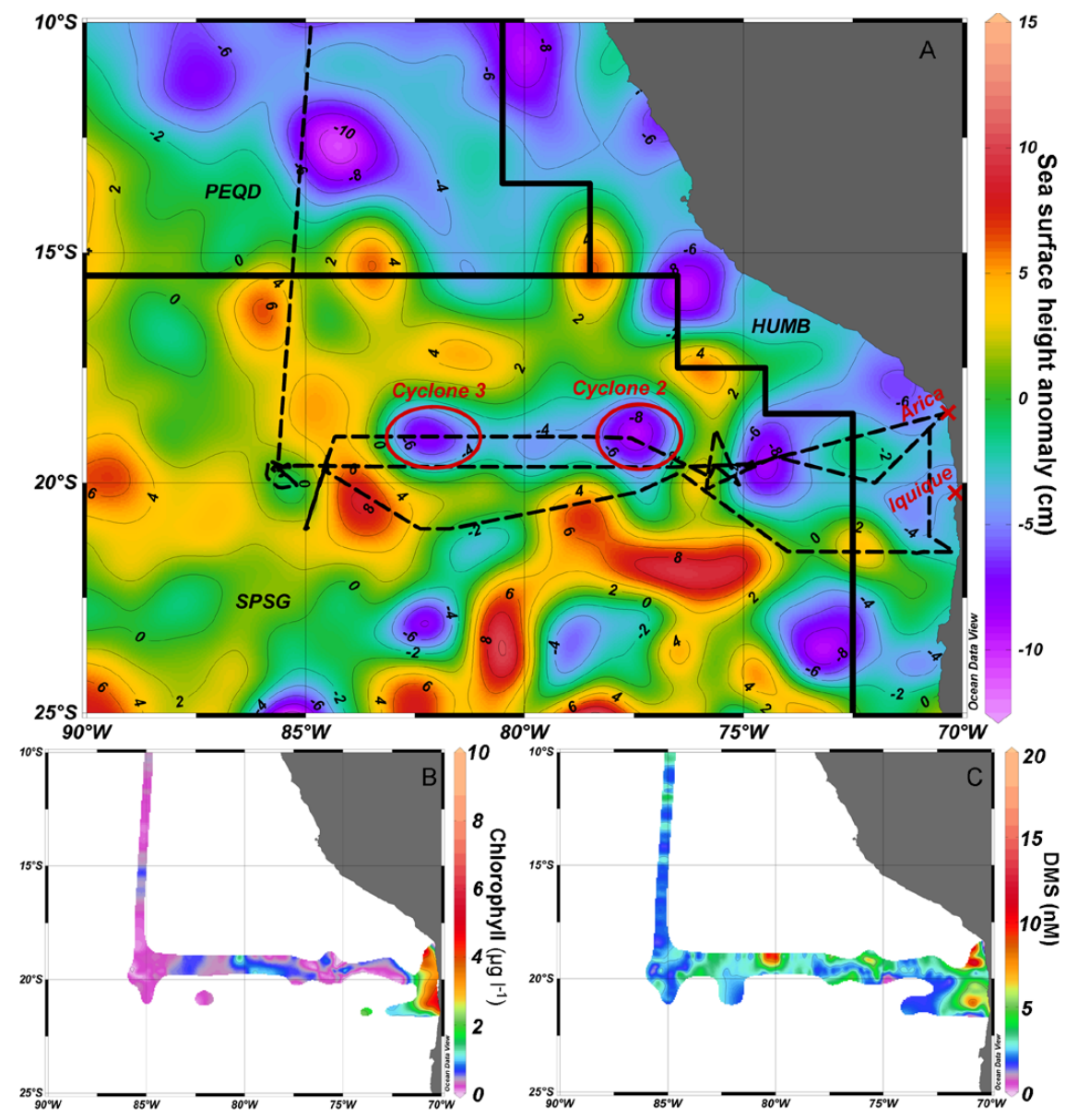

Fig. 1. The VOCALS REx study region. The ship travelled southbound from Panama to northern Chile (October-December 2008). The most northerly data reported in this paper are from $\sim 11.5^{\circ} \mathrm{S}$. Panel A shows the cruise track (black dashed line), and the colouring in this Panel represents the mean sea surface height $(\mathrm{SSH})$ anomaly $(\mathrm{cm})$ for the week 1-7 October 2008 downloaded from the AVISO website (www.aviso.oceanobs.com). The second and third cyclones encountered are labelled and marked with red ellipses. The Longhurst (1995) biogeochemical provinces Pacific Equatorial Divergence (PEQD), South Pacific Subtropical Gyre (SPSG) and Humboldt Current Coastal Province (HUMB) and the Chilean communes of Arica and Iquique are shown to provide a spatial reference. Panels B and C show in situ chlorophyll $\left(\mu \mathrm{g}^{-1)}\right.$ and DMS $(\mathrm{nM})$ respectively. These plots were produced using Ocean Data View (http://odv.awibremerhaven.de/home. html).

region, ecologically dominated by the microbial loop, rather than larger phytoplankton cells, with the euphotic zone being, on average, deeper than the mixed layer (Longhurst, 2007). DMS was variable, with concentrations between 1.3 and $4.4 \mathrm{nM}$ and a mean of $2.3 \mathrm{nM}$, close to the global mean (Kettle and Andreae, 2000). It did not co-vary clearly with either MLD or chlorophyll, although there was a net decline over the section of $\sim 0.3 \mathrm{nM} /$ degree latitude south.

\subsubsection{The South Pacific Subtropical Gyre (SPSG)}

Most of the cruise was within the SPSG province, located south of PEQD (Fig. 1). The MLD range was large, varying between 19-145 m, with a median depth of $61 \mathrm{~m}$. The chlorophyll concentration range was broad, from 0.01$2.2 \mu \mathrm{g} 1^{-1}$ with a median of $0.25 \mu \mathrm{g} \mathrm{l}^{-1}$. This is much higher than the SeaWiFS mean for the province of $0.10 \mu \mathrm{g} 1^{-1}$ for October/November 1997-2001 (Longhurst, 2007). Even for points in the SPSG west of $85^{\circ} \mathrm{W}$, more than $1500 \mathrm{~km}$ offshore, the average in situ chlorophyll concentration was still $0.16 \mu \mathrm{gl}^{-1}$ (range $0.04-0.49 \mu \mathrm{g} \mathrm{l}^{-1}$ ). This discrepancy is probably the product of several factors. SPSG is a very large province, of almost $40 \times 10^{6} \mathrm{~km}^{2}$ (the fourth largest of fifty-two globally), such that any variability will be lost in averaging; indeed, Longhurst (2007) refers to SPSG as the least well described region of the Pacific Ocean. Secondly, the stratocumulus cloud impairs the SeaWiFS "view" in this area, thereby missing observations. Marín and Delgado (2004) note that mesoscale features are not generally identified, as only partial SeaWiFS images are usually available, particularly when large scale analyses are performed. The 

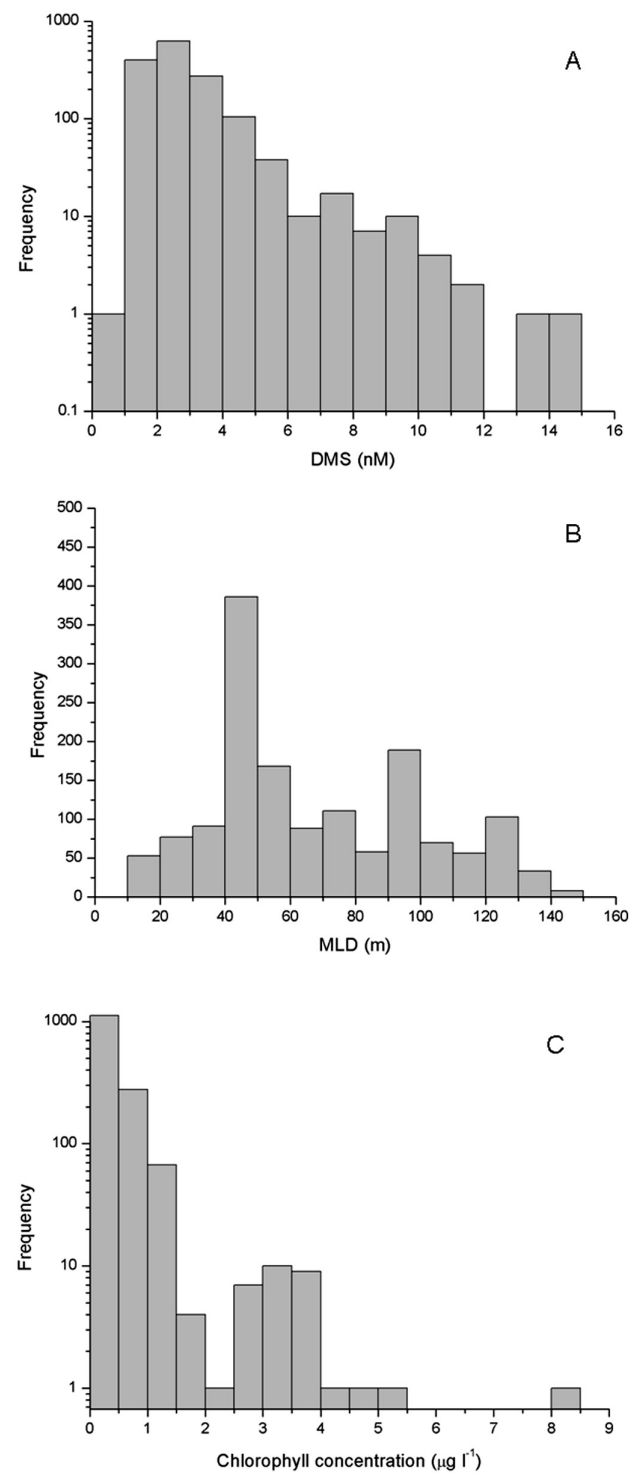

Fig. 2. Frequency plots of measured DMS (Panel A), mixed layer depth (MLD) (Panel B) and chlorophyll (Panel C).

potential errors arising from reduced satellite observations are likely compounded by the limited in situ sampling. Indeed, Longhurst (2007) describes the eastern flank of SPSG as "bounded by the offshore eddy field of the Humboldt Current," which more properly places this region in a transition zone between the SPSG "proper" and the coastal HUMB province. The range of DMS concentrations in this province was also large, $1.0-14.1 \mathrm{nM}$, with a median of $2.5 \mathrm{nM}$. Over the whole province, there was a trend of W-E shoaling of the MLD, with a mean change of $\sim 6.3 \mathrm{~m} /$ degree longitude $\left(r^{2}=0.74, \rho=0.90, n=1456\right)$ but with considerable variation related to westward propagating eddies. This strong longitudinal trend is not found in either the chlorophyll or DMS data. Over the province, there is a positive correlation

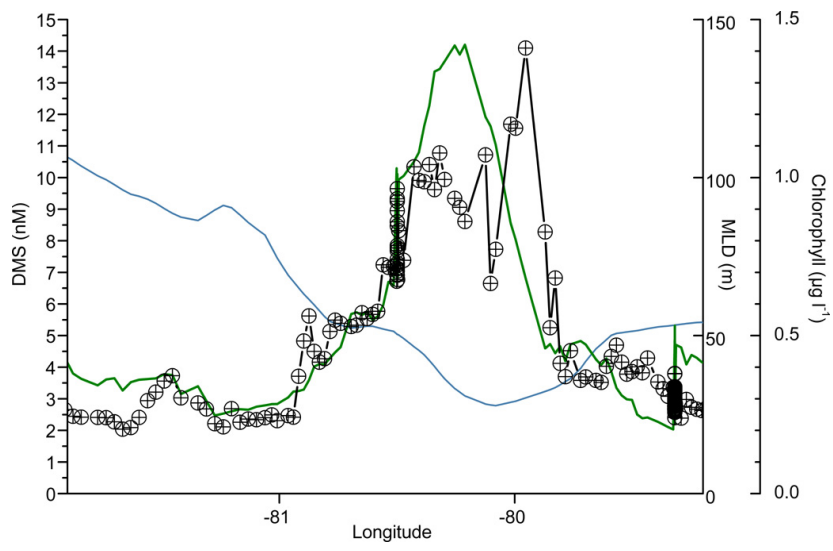

Fig. 3. The highest DMS concentrations were associated with a rapid shoaling of the mixed layer depth (MLD). Chlorophyll (green line) and DMS (black line, with crosshair symbols) concentrations increased as the MLD (blue line) shoaled. The data are plotted against longitude $\left({ }^{\circ} \mathrm{E}\right)$. The latitude was $\sim 19^{\circ} \mathrm{S}$. For reference, this is $\sim 1000 \mathrm{~km}$ from the coast.

between chlorophyll $(\mathrm{C})$ and DMS $(\mathrm{DMS}=(3.10 \times \mathrm{C})+1.78$; $\left.r^{2}=0.35, \rho=0.61, n=1324\right)$.

The highest DMS concentrations in the whole dataset, which peaked at $14.1 \mathrm{nM}$, were near $19^{\circ} \mathrm{S}, 80^{\circ} \mathrm{W}$ on the $17-$ 18 November 2008, associated with a cyclonic eddy as identified by the SSH anomaly. The feature is labelled as Cyclone 3 in Fig. 1, Panel A. As the ship travelled eastwards from $81.2^{\circ} \mathrm{W}$, the MLD shoaled from $\sim 50 \mathrm{~m}$ to $\sim 27 \mathrm{~m}$ (the shallowest MLD in this province) over a distance of about $7 \mathrm{~km}$ (Fig. 3). Over the same distance, the DMS concentration rose very sharply from a background level of $2.5-3.0 \mathrm{nM}$ to the DMS peak of $14.1 \mathrm{nM}$, observed at the shallowest mixed layer depth. Chlorophyll also rose over the same distance, from $\sim 0.4$ to $\sim 0.7 \mu \mathrm{g} \mathrm{I}^{-1}$, although the chlorophyll peak of $\sim 1.4 \mu \mathrm{g}^{-1}$ was further west than the DMS maximum, where the MLD had begun to deepen to $\sim 35 \mathrm{~m}$. The changes in MLD, chlorophyll, and DMS are plotted against longitude in Fig. 3. The elevated chlorophyll so far offshore is probably related to some local, perhaps eddy induced, upwelling that enhanced the supply of nutrients (McGillicuddy et al., 2007). However, these high DMS concentrations are not explained entirely by the elevated chlorophyll, as similar chlorophyll concentrations were found at the coast where DMS was not so elevated. Further to this, the combination of chlorophyll and MLD does not explain the high DMS. For example, at the DMS hotspot at $19^{\circ} \mathrm{S}, 80^{\circ} \mathrm{W}$, the chlorophyll concentrations were $0.6 \mu \mathrm{g} \mathrm{I}^{-1}$ and higher. However, very similar chlorophyll concentrations and MLDs were also found on the 29/30 November 2008 when DMS was much lower, at $1.6-5.3 \mathrm{nM}$, i.e. elevated in parts but not as strongly. The influence of this feature is also seen in Figure 4 even though the effect of this spike on DMS and chlorophyll concentrations is moderated by the averaging of more typical measurements 


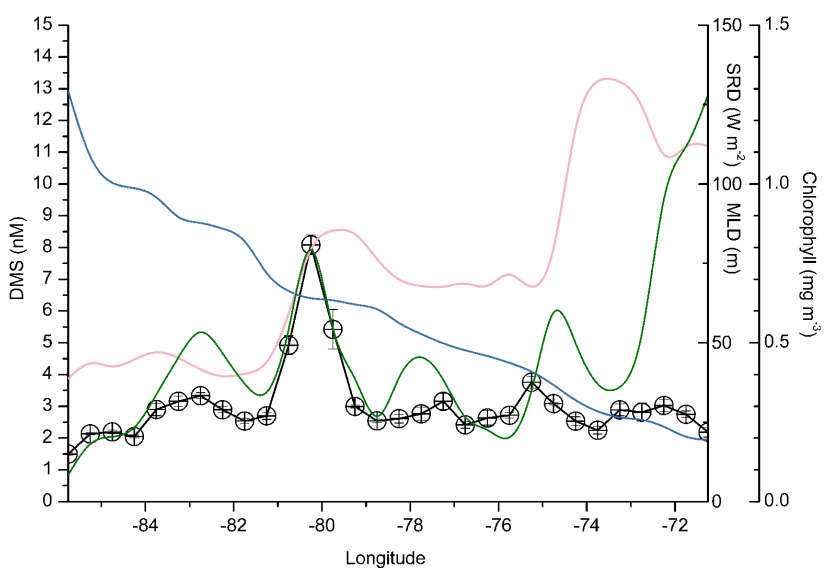

Fig. 4. A west-east section summarising the changes in seawater DMS (black), mixed layer depth (MLD) (blue), solar radiative dose (SRD) (pink) and chlorophyll (green) during the VOCALS REx cruise. The latitudinal range is $\sim 11.5-20.5^{\circ} \mathrm{S}$ although $95 \%$ of the data is between $17.0^{\circ} \mathrm{S}$ and $20.5^{\circ} \mathrm{S}$. Data are averaged over $0.5^{\circ}$ longitudinal bins. The error bars on the DMS points represent \pm 1 standard error. All data were in situ or derived from in situ data. MLD is defined as a change of $0.1^{\circ} \mathrm{C}$ from $10 \mathrm{~m}$ depth. SRD and MLD share the same axis to aid readability.

$\left(\sim 11.5-20^{\circ} \mathrm{S}\right)$ binned over $0.5^{\circ}$ longitude taken during an earlier (28-29 October) transect at $19.7^{\circ} \mathrm{S}$, about $110 \mathrm{~km}$ north of this section.

\subsubsection{The Humboldt Current Coastal Province (HUMB)}

In the narrow HUMB province, the MLD was shallow with a median depth of $19 \mathrm{~m}$ and the range of $\sim 16-25 \mathrm{~m}$. Chlorophyll and DMS concentrations were highly variable; chlorophyll was between 0.03 and $8.22 \mu \mathrm{g}^{-1}$ with a median of $1.32 \mu \mathrm{g} 1^{-1}$, and DMS was from $1.3-13.4 \mathrm{nM}$ with a median of $2.6 \mathrm{nM}$. The chlorophyll mean $\left(1.32 \mu \mathrm{g} 1^{-1}\right)$ was again much greater than the SeaWiFS mean for the province of $0.70 \mu \mathrm{g}^{-1}$ for October/November 1997-2001 (Longhurst, 2007). There remains a correlation between MLD and longitude, the depth reduces by $\sim 2.7 \mathrm{~m} /$ degree longitude east $\left(r^{2}=0.46, \rho=0.71, n=89\right)$. The MLD definition used (a temperature deviation of $0.1^{\circ} \mathrm{C}$ from $10 \mathrm{~m}$ ) makes it unlikely for MLD values to be much smaller than this. In the HUMB province, the correlation between chlorophyll and DMS was stronger than in the other provinces $(\mathrm{DMS}=(5.31 \times \mathrm{C})+$ $0.16 ; r^{2}=0.41, \rho=0.69, n=89$ ).

\subsection{Regional patterns}

In order to describe the trends in MLD, DMS, and SRD over the whole cruise especially, as most sampling was conducted within a narrow latitudinal band, the MLD, chlorophyll, DMS, and SRD data were averaged over $0.5^{\circ}$ longitudinal bins, as shown in Fig. 4. The strong trend was the eastward shoaling of MLD of $\sim 5.8 \mathrm{~m} /$ degree longitude $\left(r^{2}=0.72\right.$, $\rho=0.90, n=1632$ ). Again, there was a positive correlation between chlorophyll and DMS over the whole region (DMS $\left.=(3.10 \times \mathrm{C})+1.78 ; r^{2}=0.35, \rho=0.57, n=1531\right)$. As the SRD is strongly influenced by the MLD, it strongly and negatively correlated with it.

The two featured MLD climatologies, ML97 and BM04, reported a shallower MLD than was determined from the in situ measurements, with BM04 being shallowest (See Table 1). The correlations between the MLD values are strong, with the greatest being between the in situ and BM04 data $\left(r^{2}=0.83, \rho=0.92, n=1538\right)$, followed by that between ML97 and BM04 $\left(r^{2}=0.72, \rho=0.89, n=1538\right)$. The least well correlated were the in situ and M197 data $\left(r^{2}=0.64\right.$, $\rho=0.81, n=1538$ ).

For each sampling point, the mean in situ SW irradiance over the preceding $24 \mathrm{~h}$ is summarised in Table 1 . The mean and the median values were similar, but the in situ measurements were much more variable than the estimates from TOA/2. The average percentage of the top of atmosphere SW irradiance that reached the surface was 53\% and the median was $52 \%$. Thus, the use of Vallina and Simó's (2007) assumption that $50 \%$ of the incident radiation was lost in the atmosphere was a good approximation (for a fixed value). The in situ data showed a weak, yet significant trend, with latitude $(\mathrm{S}-\mathrm{N})$ of $\sim 4 \mathrm{~W} \mathrm{~m}^{-2}$ /degree $\left(r^{2}=0.02, \rho=0.31, n=1538\right)$ and a net decrease with longitude (W-E) of $\sim 2.3 \mathrm{~W} \mathrm{~m}^{-2} /$ degree $\left(r^{2}=0.01, \rho=0.10\right.$, $n=1538$ ). In both cases there was significant variability so that the correlations were weak yet significant. The longitudinal change in $\mathrm{SW}$ irradiance of $\sim 2.3 \mathrm{~W} \mathrm{~m}^{-2}$ /degree is in agreement with longer term measurements. During 2007, the mean SW irradiance at the WHOI/Stratus buoy $\left(19.7^{\circ} \mathrm{S}\right.$, $85.6^{\circ} \mathrm{W}$ ) was $206 \mathrm{~W} \mathrm{~m}^{-2}$, whilst, over the same period at the SHOA/DART buoy $\left(19.6^{\circ} \mathrm{S}, 74.8^{\circ} \mathrm{W}\right)$ the average was $178 \mathrm{~W} \mathrm{~m}^{-2}$ (Robert Weller, WHOI, personal communication, 2009); this represents a change of $\sim 2.6 \mathrm{~W} \mathrm{~m}^{-2}$ /degree longitude. The TOA/2 values increased with latitude by $\sim 2 \mathrm{~W} \mathrm{~m}^{-2} /$ degree, so the net effect of the change in cloud cover southwards is $\sim 6 \mathrm{~W} \mathrm{~m}^{-2} /$ degree. There was a small longitudinal trend in the TOA $/ 2$ data of $\sim 0.3 \mathrm{~W} \mathrm{~m}^{-2} /$ degree. This resulted from the increase in day length over the duration of the cruise. The net effect of the clouds is a decrease of $\sim 2.6 \mathrm{a} \mathrm{W} \mathrm{m}^{-2} /$ degree. The in situ and TOA/2 datasets do not correlate strongly $\left(r^{2}=0.10, \rho=0.334, n=1538\right)$, although the relationship is again significant.

For each sample, the UV irradiance at noon on that day was determined from both TUV and in situ measurements. There are minor trends in the TUV data. The UV level from TUV increased slightly with distance southwards $(\sim 1.1 \%$ /degree) but the strength of the relationship was weak $\left(r^{2}=\right.$ 0.0731, $\rho=0.077, n=1538$ ). The W-E trend was a little larger $(\sim 1.3 \%$ /degree $)$ and the relationship was much stronger $\left(r^{2}=0.95, \rho=0.95, n=1538\right)$. The measured data showed a small decline in UV southward and no significant 
variation with longitude. There is a weak correlation between TUV and the measured data $\left(r^{2}=0.05, \rho=0.09, n=1408\right)$. The correlation between measured UV and measured irradiance is stronger $\left(r^{2}=0.10, \rho=0.56, n=1338\right)$. The means, medians, maxima and minima of the TOA/2, TUV, and the measured equivalents are given in Table 1.

There was some discrepancy between the in situ and SeaWiFS chlorophyll with the former generally being higher (median 0.26 vs. $0.18 \mu \mathrm{g} \mathrm{l}^{-1}$ ). The range of the former was larger, with smaller and greater values than in the SeaWiFS data. The smaller range would be expected owing to the spatial and temporal averaging involved in the SeaWiFS data preparation.

\subsection{Climatology and algorithm comparisons}

Many predicted DMS concentrations have been reported, derived from several algorithms based on a small number of parameters, as briefly discussed earlier. The DMS predicted concentrations during VOCALS REx 2008 cruise by the various climatologies and algorithms discussed herein are summarised in Table 2.

In the study region, the K99 and K00 data are similar, as expected, although those from K00 are a little lower; the difference between the means is $\sim 0.1 \mathrm{nM}$. Both K99 and K00 are similar to measured values, although the mean residuals are both $\sim 1.0 \mathrm{nM}$, with very small differences between the mean and median values over the study region (Table 2 ). The differences between the measured and the predicted DMS are plotted by longitude in Fig. 5. Both give values above and below the measured concentrations (52\% of the K99 and 47\% of the K00 values are larger than measured). K99 and K00 substantially underestimate DMS around $79-80^{\circ} \mathrm{W}$, where the measured DMS values were high along the $\sim 19^{\circ} \mathrm{S}$ transect (Figs. 3, 4 and 5).

The BE04 DMS estimates were derived entirely from chlorophyll concentrations. The algorithm was tested with both in situ and SeaWiFS chlorophyll data. The algorithm performed poorly in both cases. In general, as also reported by Belviso and colleagues (2004a) in their study, DMS was underestimated in this SE Pacific study in $\sim 85 \%$ of cases.

In this analysis, the AN01 algorithm reproduced the observed pattern of DMS fairly well, although many of the sampling sites were in waters where a constant DMS value of $2.29 \mathrm{nM}$ was assigned. This occurred at $\sim 75 \%$ of the sampling sites, when using either calculated or in situ measured irradiance. The TOA/2 SW irradiance data with the in situ chlorophyll resulted in the best performing parameterisation of all tested, followed closely by the in situ irradiance also with the in situ chlorophyll. In contrast to the choice of irradiance data the DMS predicted using AN01 was very sensitive to the source of the chlorophyll data. The performance using SeaWiFS was much poorer than with the in situ measurements.

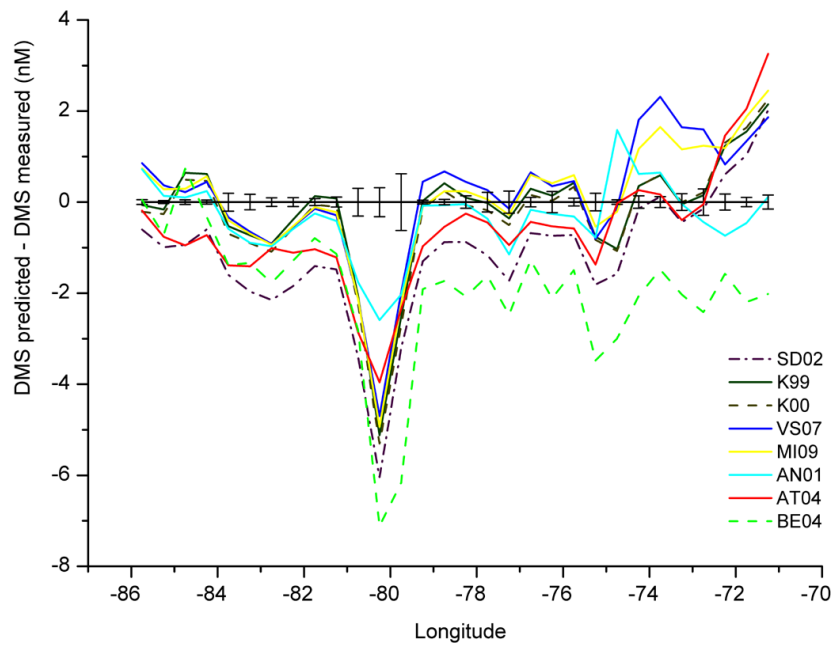

Fig. 5. The difference between predicted DMS and measured DMS concentrations plotted against longitude for the VOCALS REx cruise in the SE Pacific. The measured DMS is plotted as 0 and the error bars represent 1 standard error. For each predicted DMS dataset, the optimum parameters were chosen as determined using the overall ranking system shown in Table 5.3. The data are in $0.5^{\circ}$ longitude bins. The algorithm acronyms are explained in the text.

The SD02 DMS concentration was determined using each of the three MLD sets and the in situ chlorophyll; the data are given in Table 2. In this region, the SD02 algorithm did not perform very well. The best performance was obtained using in situ MLD data, followed by the BM04 and the ML97 climatologies. The values of the predicted DMS concentrations were sensitive to the choice of MLD. Using the in situ MLD data produced the lowest DMS values, with a mean of $1.8 \mathrm{nM}$ and a median of $1.7 \mathrm{nM}$. Using the ML97 values gave a DMS mean of $2.4 \mathrm{nM}$ and a similar median of $1.8 \mathrm{nM}$. When the BM04 MLD values were used, the predicted DMS values were much higher than for either the in situ or the ML97 MLD datasets.

The DMS concentrations predicted using AT04 were again sensitive to the choice of MLD. This was because, at the majority of the data points AT04 had C/MLD $<0.02 \mathrm{mg} \mathrm{m}^{-2}$, being the division between the SD02 two part relationship. This was similar to the SD02 algorithm results, using the same criteria. As the in situ MLDs were the deepest of the three MLD datasets, they gave the lowest DMS concentration estimations and, of the three MLD datasets, overall in situ performed the best. However, the strongest individual AT04 performance was obtained using the BM04 MLD and a constant of $30 \mu \mathrm{mol} \mathrm{m}^{-2}$. This combination was the 4 th best of all algorithms/variable combinations tested (Table 2). In this best case scenario, the AT04 relationship was a significant improvement over SD02 for the VOCALS REx region. However, it did not perform as well as in the original paper or when tested by Miles et al. (2009). 
Table 2. A summary of predicted DMS values and the relation of these to the measured values. The table contains the predictor type (algorithm or climatology code), mixed layer depth (MLD), chlorophyll and irradiance data used, the mean and median DMS (nM). Also $n$, the slope and the intercept of the regression, the mean residual $(\bar{e}, \mathrm{nM})$, the correlation coefficient $\left(r^{2}\right)$, and Spearman's rank correlation coefficient $(\rho)$ are given. All $\rho$ are significant at $p<0.01$, excepting AN01 with SeaWiFS chlorophyll and TOA/2 irradiance. The columns to the right of $\bar{e}, r^{2}$ and $\rho$ are the rank of that metric in relation to the other predictors, numbered $1-23,1$ being the best performing. The final column is the overall position, the order (smallest to largest) of the sum of the ranks for the metrics. For reference, the mean and median of all measured DMS data were 2.5 and 2.9 nM. For VS07 and MI09, the best performing couplets are also given (in Table 4).

\begin{tabular}{|c|c|c|c|c|c|c|c|c|c|c|c|c|c|c|c|}
\hline Type & MLD & Chlorophyll & Irradiance & Mean & Median & $n$ & slope & intercept & $\bar{e}$ & $\bar{e}$ rank & $r^{2}$ & $r^{2}$ rank & $\rho$ & $\rho$ rank & Overall rank \\
\hline AN01 & - & in situ & $\mathrm{TOA} / 2$ & 2.9 & 2.3 & 1374 & 0.71 & 0.83 & 0.85 & 1 & 0.32 & 1 & 0.53 & 3 & 1 \\
\hline AN01 & - & in situ & in situ & 2.8 & 2.3 & 1374 & 0.66 & 0.95 & 0.88 & 2 & 0.31 & 2 & 0.55 & 2 & 2 \\
\hline MI09 & in situ & - & TUV & 2.9 & 2.8 & 1538 & 6.53 & 1.82 & 0.89 & 3 & 0.12 & 6 & 0.49 & 4 & 3 \\
\hline AT04 30 & BM04 & - & - & 2.0 & 1.8 & 1394 & 0.68 & 1.49 & 1.06 & 10 & 0.20 & 3 & 0.56 & 1 & 4 \\
\hline VS07 & in situ & - & $\mathrm{TOA} / 2$ & 2.9 & 2.8 & 1538 & 0.02 & 1.46 & 0.89 & 3 & 0.14 & 4 & 0.46 & 8 & 5 \\
\hline AT04 60 & in situ & - & - & 1.1 & 1.1 & 1394 & 0.71 & 2.04 & 1.78 & 19 & 0.10 & 7 & 0.46 & 7 & 6 \\
\hline SD02 & in situ & - & - & 1.6 & 1.7 & 1394 & 0.78 & 1.60 & 1.33 & 15 & 0.09 & 9 & 0.43 & 10 & 7 \\
\hline AT04 30 & in situ & - & - & 0.7 & 0.5 & 1394 & 0.69 & 2.39 & 2.23 & 23 & 0.10 & 8 & 0.47 & 6 & 8 \\
\hline AT04 60 & ML97 & - & - & 1.3 & 1.2 & 1394 & 0.61 & 2.36 & 1.58 & 17 & 0.07 & 11 & 0.43 & 9 & 8 \\
\hline AT04 90 & in situ & - & - & 1.6 & 1.6 & 1394 & 0.56 & 1.96 & 1.39 & 16 & 0.08 & 10 & 0.42 & 11 & 8 \\
\hline AT04 30 & ML97 & - & - & 0.8 & 0.6 & 1394 & 0.61 & 2.36 & 2.08 & 22 & 0.07 & 11 & 0.48 & 5 & 11 \\
\hline AT04 90 & ML97 & - & - & 1.9 & 1.7 & 1394 & 0.57 & 2.09 & 1.25 & 13 & 0.06 & 13 & 0.38 & 12 & 11 \\
\hline K00 & - & & - & 2.5 & 2.7 & 1538 & 0.53 & 1.52 & 1.00 & 8 & 0.06 & 14 & 0.26 & 16 & 11 \\
\hline K99 & - & & - & 2.6 & 2.9 & 1538 & 0.56 & 1.39 & 1.01 & 9 & 0.06 & 14 & 0.27 & 15 & 11 \\
\hline HI 141 & in situ & - & - & 2.6 & 2.1 & 1491 & 0.19 & 2.33 & 1.27 & 14 & 0.06 & 14 & 0.37 & 13 & 15 \\
\hline SD02 & BM04 & - & - & 2.8 & 2.6 & 1394 & 0.52 & 1.42 & 0.93 & 7 & 0.05 & 17 & 0.25 & 17 & 15 \\
\hline SD02 & ML97 & - & - & 1.8 & 1.7 & 1394 & 0.59 & 1.79 & 1.18 & 12 & 0.04 & 18 & 0.37 & 14 & 17 \\
\hline AN01 & - & SeaWiFS & in situ & 2.3 & 2.3 & 1350 & 0.00 & 2.33 & 0.90 & 5 & 0.00 & 23 & 0.21 & 18 & 18 \\
\hline BE04 & - & SeaWiFS & - & 1.4 & 1.1 & 1509 & -0.18 & 1.87 & 1.79 & 20 & 0.14 & 5 & -0.52 & 22 & 19 \\
\hline AN01 & - & SeaWiFS & $\mathrm{TOA} / 2$ & 2.3 & 2.3 & 1350 & 0.00 & 2.31 & 0.91 & 6 & 0.00 & 22 & 0.04 & 21 & 20 \\
\hline AT04 60 & BM04 & - & - & 3.0 & 2.6 & 1394 & 0.26 & 2.08 & 1.08 & 11 & 0.02 & 19 & 0.17 & 19 & 20 \\
\hline AT04 90 & BM04 & - & - & 4.0 & 3.8 & 1394 & -0.15 & 3.44 & 1.93 & 21 & 0.02 & 20 & 0.15 & 20 & 22 \\
\hline BE04 & - & in situ & - & 1.5 & 1.2 & 1394 & 0.08 & 1.16 & 1.63 & 18 & 0.02 & 21 & -0.69 & 23 & 23 \\
\hline
\end{tabular}

In the case of AT04 run with the BM04 MLD and a constant of $30 \mu \mathrm{mol} \mathrm{m}{ }^{-2}$, its success was both from the combined estimates of the high $(\mathrm{C} / \mathrm{MLD}>0.02, n=1394)$ and the low $(\mathrm{C} / \mathrm{MLD}<0.02, n=409)$ parts of the relationship. The $r^{2}$ and $\rho$ values for the high part alone were 0.02 and 0.56 respectively while for the low part these were 0.09 and 0.55 .

As when using the AT04 relationship, the in situ MLD dataset was the best overall for estimating the DMS concentrations, we used the in situ MLD values to determine the constant which estimated a DMS dataset with the smallest median modulus value, using the method of Bell et al. (2006). The constant, $141 \mu \mathrm{mol} \mathrm{m}^{-2}$, produced a dataset with a median modulus value of $0.99 \mathrm{nM}$ and a mean residual of $1.27 \mathrm{nM}$. However, whilst this fitted constant gave the lowest residual, the other metrics indicated a worse fit than when using the AT0 4 constants of 30,60 or $90 \mu \mathrm{mol} \mathrm{m}^{-2}$ (Table 2).

We attempted to merge the overall most successful algorithm, AN01, with AT04 which had previously been found to perform well in low DMS regions (Bell et al., 2006). We used the "low DMS" part of the AT04 relationship where AN01 would assign the low DMS value of $2.29 \mathrm{nM}$ (s):

$\mathrm{DMS} \times \mathrm{MLD}=$ constant, $\log _{10}(\mathrm{CJQ}) \leq s$

$\mathrm{DMS}=b\left[\log _{10}(\mathrm{CJQ})-s\right]+a, \log _{10}(\mathrm{CJQ}) \succ s$ where chlorophyll $\left(\mathrm{C}, \mu \mathrm{g} \mathrm{l}^{-1}\right)$, irradiance $\left(\mathrm{J}, \mathrm{W} \mathrm{m}^{-2}\right)$ and a nitrate limitation term, the Michaelis-Menten nutrient limitation factor $(\mathrm{Q}$, dimensionless) are employed.

For the first (low DMS) part, we tried both the best performing combination of the BM04 MLD and a constant of $30 \mu \mathrm{mol} \mathrm{m} \mathrm{m}^{-2}$ and also the in situ MLD and the constant of $60 \mu \mathrm{mol} \mathrm{m}^{-2}$. For the constants $a, b$, and $s$ we used the original AN01 values. However, this modification did not perform more strongly than AN01 (data not shown). When the in situ MLD data were used, $91 \%$ of the sampling points had C/MLD $<0.02 \mathrm{mg} \mathrm{m}^{-2}$, while fewer sampling points were in this category when using either the ML97 $(85 \%)$ or the BM04 (65\%) MLD climatologies.

The SRD was calculated for each of the possible combinations of the three MLD dataset choices and each of the four SW irradiance/UV datasets. For those determined using SW irradiance (rather than UV), each of the three VS07 regression lines (optimised for Blanes Bay, Sargasso Sea or the Global Ocean) were applied. Additionally, the line of best fit to the measured data with the largest $r^{2}$ value was used. As MI09 did not report a regression line for the UVRD relationship, only the best fit line was tested. Table 3 shows the mean residuals $(\bar{e})$ for the possible MLD/irradiance combinations. Overall, on the basis of the size of the mean residual for each combination, the Global Ocean relationship was the strongest, followed by the local Sargasso Sea and Blanes 
Table 3. Mean residuals $(\bar{e}, \mathrm{nM})$ between measured DMS concentrations and those predicted by VS07, using all mixed layer depth (MLD) and irradiance (IR) data combinations and the three linear relationships reported in Vallina and Simó (2007). The first column indicates which of the three mixed layer depth (MLD) datasets was used, determined in situ or from the ML97 or BE04 climatologies. The second column contains the incoming radiation (IR) dataset used, either shortwave radiation measured in situ (SW is) or the estimated surface shortwave radiation (TOA/2). Further details of these data are given in the methods section. The relationships were determined for: $a=$ Blanes Bay, DMS $=0.138+0.028$.SRD; $b=$ the global ocean, DMS $=0.492+0.019 . \mathrm{SRD}$ and $c=$ the Sargasso Sea, $\mathrm{DMS}=0.51+0.017 . \mathrm{SRD}$.

\begin{tabular}{lllll}
\hline \multicolumn{2}{l}{ Datasets used to calculate SRD } & \multicolumn{3}{c}{$\bar{e}$ (nM) } \\
\hline MLD & IR & $a$ & $b$ & $c$ \\
in situ & SW is & 1.13 & 1.22 & 1.31 \\
in situ & TOA/2 & 1.17 & 1.26 & 1.34 \\
ML97 & SW is & 1.03 & 1.08 & 1.15 \\
ML97 & TOA/2 & 1.01 & 1.10 & 1.19 \\
BM04 & SW is & 1.70 & 1.13 & 1.03 \\
BM04 & TOA/2 & 1.40 & 0.96 & 0.89 \\
\hline
\end{tabular}

Bay relationships. The Sargasso Sea relationship, when combined with the BM04 MLD and TOA/2 datasets, was the best performing with a mean residual of $0.89 \mathrm{nM}$. This is perhaps unsurprising as the MLD and irradiance choices were the same used to derive the original relationship.

In assessing the performance of the variables used in VS07 and MI09, it was clear that the best MLD choice was the in situ dataset (Table 4). There was little difference observed between the predictions based on ML97 and BM04. This is in contrast to MI09, who found that climatological MLD was better than in situ data at predicting the DMS concentration. The choice of irradiance was less critical, as the MLD definition dominated the performance ranking. The light parameter datasets, ranked in descending order, beginning with the most useful, are as follows: TOA/2, TUV, SW in situ, and UV in situ. Whereas the performance varied by metric, the calculated irradiance/UV values performed better overall than the in situ ones, in agreement with Miles et al. (2009). Similar to the Miles et al. (2009) results, the slope of the regression line of SRD plotted against measured DMS was much shallower than in the original paper (see Tables 2 and 4).

\section{Conclusions}

The application of published algorithms to this dynamic tropical oligotrophic-eutrophic zone is a useful companion to the oligotrophic tropical and subtropical comparison studies of Bell et al. (2006) and Miles et al. (2009) as well as to the temperate ones of Belviso and co-workers (Belviso et al., 2004a;
Belviso and Caniaux, 2009). Furthermore, as a strength of analysis, the latitudinal range was small and the sampling occurred over a fairly short period, so seasonal effects were likely small yet the MLD and productivity varied greatly, providing a comprehensive dataset for comparison and validation of algorithms.

Interest in the SE Pacific region stems from the need to realistically model its radiative budget and this requires a quantitative description of its stratocumulus clouds and their complex aerosol microphysics. The source of aerosols could be either homogeneous nucleation from local gas-phase precursors or entrainment of land-derived pollution particles from above the marine boundary layer inversion. In either case, the particles probably grow to become effective cloud condensation nuclei by adding sulphate derived from DMS (and probably also biogenic organic material). Quantifying a natural source requires the understanding of the oxidation of DMS to sulphate aerosol, its flux to the atmosphere and, ultimately, its biological production and resulting net seawater concentration; predicting the required DMS concentrations is addressed here. Unfortunately, in this study we were unable to study the influence of POCs on the DMS concentration, as we passed under only one during the fieldwork and any variability observed in the measurements during this period was more likely in response to ocean physical variability.

Predictive algorithms have been devised to estimate oceanic DMS concentrations in order to better understand DMS processes and to provide atmospheric scientists with evenly distributed climatologies from which accurate flux data can be derived. The unavailability of a reliable global climatology for DMS is mostly due to the limited number of in situ measurements. We have applied a number of published algorithms to the SE Pacific and validated the results with the high resolution surface DMS measurements made during the VOCALS REx expedition. In Fig. 5 the difference between the measured and estimated DMS concentrations is plotted against latitude for each algorithm or climatology. The surface seawater DMS measurements observed in the SE Pacific were not reproduced very well by any of the algorithms. At best, the mean residual was of the order of $30 \%$ of the measured values and, at worst, $\sim 90 \%$. The highest Spearman's correlation $(\rho)$ between measured and predicted values was 0.56 , which was lower than that found by either Miles et al. (2009) or Vallina and Simó (2007). Overall, the data were best reproduced by Anderson et al. (2001). In this case, the uncertainty in the seawater DMS concentrations was smaller than the uncertainty in the gas transfer velocity which is around a factor of 1.5 for the moderate windspeeds of the region (Kettle and Andreae, 2000; Calleja et al., 2009 and references therein). AN01 performed better than the other algorithms notably in offshore eddy and productive coastal conditions (see Figure 5). At the offshore hotspot, all estimates were too low, although AN01 was too low by the least. In the coastal waters (east of $\sim 73^{\circ} \mathrm{W}$ ), all algorithms, excepting AN01, overestimated DMS concentrations. The 
Table 4. Performance summary for the VS07 and MI09 relationships. These values were determined from the regression equations as applied to the SE Pacific region. The first column indicates which of the three mixed layer depth (MLD) datasets was used, these were either determined in situ or from the ML97 or BE04 climatologies. The second column contains the incoming radiation (IR) dataset used, one of shortwave radiation measured in situ (SW is), the estimated surface shortwave radiation (TOA/2), UV radiation from the NCAR Tropospheric Ultraviolet and Visible Radiation Model (TUV) or UV measured in situ (UV is). Further details of these data are given in the methods section. The following columns contain the number of points $(n)$, the slope and intercept of the relationship, the mean residuals $(\bar{e}$, nM), the correlation $\left(r^{2}\right)$ and the Spearman coefficients $(\rho)$. In the column to the right of each of the assessment criteria the rank (ascending) is given. The final column is the overall performance rank based on the sum of the three other scores.

\begin{tabular}{lllllllllllll}
\hline MLD & IR & $n$ & Slope & Intercept & $\bar{e}$ & $\bar{e}$ rank & $r^{2}$ & $r^{2}$ rank & $\rho$ & $\rho$ rank & Overall \\
\hline in situ & TOA/2 & 1538 & 0.02 & 1.46 & 0.89 & 2 & 0.14 & 2 & 0.46 & 2 & 1 \\
in situ & TUV & 1538 & 6.53 & 1.82 & 0.89 & 4 & 0.12 & 3 & 0.49 & 1 & 2 \\
in situ & SW is & 1538 & 0.02 & 1.63 & 0.91 & 5 & 0.12 & 4 & 0.45 & 3 & 3 \\
BM04 & TUV & 1538 & 5.32 & 0.73 & 0.89 & 1 & 0.08 & 8 & 0.45 & 4 & 4 \\
BM04 & TOA/2 & 1538 & 0.03 & -1.45 & 0.89 & 3 & 0.09 & 5 & 0.44 & 5 & 5 \\
in situ & UV is & 1338 & 0.12 & 1.77 & 0.96 & 7 & 0.14 & 1 & 0.43 & 8 & 6 \\
ML97 & TOA/2 & 1632 & 0.01 & 1.85 & 0.98 & 9 & 0.08 & 7 & 0.44 & 7 & 7 \\
ML97 & TUV & 1632 & 3.26 & 2.21 & 0.98 & 10 & 0.07 & 9 & 0.44 & 6 & 8 \\
ML97 & SW is & 1538 & 0.01 & 2.11 & 0.94 & 6 & 0.03 & 11 & 0.39 & 9 & 9 \\
ML97 & UV is & 1408 & 0.06 & 2.24 & 1.06 & 12 & 0.09 & 6 & 0.39 & 10 & 10 \\
BM04 & UV is & 1338 & 0.05 & 1.8 & 1.01 & 11 & 0.05 & 10 & 0.34 & 11 & 11 \\
BM04 & SW is & 1538 & 0.00 & 2.59 & 0.97 & 8 & 0.00 & 12 & 0.10 & 12 & 12 \\
\hline
\end{tabular}

in situ chlorophyll concentration, whilst not explaining all variability, did correlate with DMS concentration. The best performing algorithms, AN01 and AT04, do use chlorophyll as a variable, while VS07 and MI09 do not. AN01 also underestimated DMS by the least at the offshore DMS hotspot. Despite this good performance, it did not reproduce the variability in the lower-level DMS regions. This was recognised in the original paper as well as in subsequent studies (Anderson et al., 2001; Bell et al., 2006; Belviso et al., 2004a). Attempts to merge AN01 with the next most successful algorithm, AT04, did not improve the DMS predictions in this study, although this approach might be useful when considering similar regions with substantial gradients of primary production.

The SRD and UVRD relationships reproduced DMS concentrations reasonably well, with MI09 performing slightly better than VS07. This is interesting, as the MI09 algorithm was used with climatological UVR noon data, which might not be expected to be a very good predictor of the total UV irradiance, as it does not account for day length, variability in cloud, or day length change (although this last factor would be small during the course of the VOCALS REx cruise). Indeed, the algorithms always estimated DMS concentrations more accurately when either the TOA/2 SW or the TUV UVR irradiance was used in place of in situ measurements. This suggested that if the irradiance (SW or UV) was important in modulating seawater DMS concentrations, it was over longer timescales than one day, as these climatology data are probably closer to average conditions over a number of days than the in situ data. It may be that the bio- logical processes governing DMS concentration are sensitive to the light history. On the other hand, the MLD choice that resulted in the best algorithm performance in most cases (excepting the case of AT04 with the BM04 MLD) was the in situ dataset, in contrast to previous findings where climatological values were found to be superior (Miles et al., 2009; Bell et al., 2006). Perhaps this was because the MLD in the VOCALS REx study was quite variable over small distances, a detail that would be lost in a climatology, whereas the MLD trends in the AMT studies were more gradual and less influenced by mesoscale features. As the TOA/2 and TUV irradiance data did not change very much, the only significant source of variation in the input to these algorithms was the MLD. When DMS concentrations were high, the MLD was usually shallow, although a shallow MLD did not always co-occur with high DMS values. This was especially true further east (e.g. 30 November, $21.5^{\circ} \mathrm{S}, 71^{\circ} \mathrm{W}$, DMS was only $2-3 \mathrm{nM}$ while the MLD was only $16-22 \mathrm{~m}$ ). The expectation that a shallow MLD will cause high DMS concentrations was the source of the overestimations of DMS by all of the algorithms that used MLD, and not AN01. The Kettle databases also have high DMS concentrations at these most easterly locations, likely due to the very high inshore concentrations measured by Andreae (1985). As the uncertainty in DMS predictive algorithms is still substantial and as studies in different locations, times, or scales often do not agree, caution must be used when such algorithms are used to predict changes in flux of DMS to the atmosphere in future climate scenarios. 
In summary, to predict surface seawater concentrations in this region of the SE Pacific, the Anderson et al. (2001) algorithm (AN01), using in situ chlorophyll and nitrate data coupled with the estimated surface SW irradiance values from TOA/2, was found to be most effective. It must be reiterated that this algorithm does not reproduce the changes in DMS in the more oligotrophic areas but does capture the variability produced by offshore eddy features and near the coast better than any other. However, when SeaWiFS data were employed, the performance of AN01 was greatly reduced. In more oligotrophic waters in general, AT04, VS07 and MI09 have been found to be better choices (e.g. Bell et al., 2006; Miles et al., 2009). Combining AN01 with one of these may offer the best solution for resolving DMS variability in disparate regions, although a process model that replicates the biology, chemistry and physics of DMS production and loss processes is ultimately desirable.

Acknowledgements. We thank Barry Huebert and Rebecca Simpson for their assistance in operating and QC'ing the semicontinuous DMS data; Fiamma Straneo and Carlos Moffat for performing the MLD calculations; Chris Bretherton and his group for the SW radiation data; Thomas Balch for his help in processing the in situ UV data; and Robert Weller and Chris Bretherton for their leadership in the field. Victoria Hill kindly loaned us the Satlantic radiometer. We also thank Sergio Vallina for sharing the recalculated de Boyer Montégut et al. MLD dataset, Alan Longhurst for the useful spreadsheets, and Tom Bell, Chris Miles and Jamie Kettle for useful advice. Julia Cotterill patiently proof read the final version. Finally, we thank S. Belviso and an anonymous reviewer for their most helpful comments and suggestions. Financial support for this work was provided by an NSF Chemical Oceanography grant (OCE-0741817).

Edited by: L. Bopp

\section{References}

Anderson, T. R., Spall, S. A., Yool, A., Cipollini, P., Challenor, P. G., and Fasham, M. J. R.: Global fields of sea surface dimethylsulfide predicted from chlorophyll, nutrients and light, J. Mar. Syst., 30, 1-20, 2001.

Andreae, M. O.: Dimethylsulfide in the water column and the sediment pore waters of the Peru upwelling area, Limnol. Oceanogr., 30, 1208-1218, 1985.

Aranami, K. and Tsunogai, S.: Seasonal and regional comparison of oceanic and atmospheric dimethylsulfide in the northern North Pacific: dilution effects on its concentration during winter, J. Geophys. Res., 109, D12303, doi:10.1029/2003JD004288, 2004.

Aumont, O., Belviso, S., and Monfray, P.: Dimethylsulfoniopropionate (DMSP) and dimethylsulfide (DMS) sea surface distributions simulated from a global three-dimensional ocean carbon cycle model, J. Geophys. Res.-Ocean., 107(C4), 3029, doi:10.1029/1999JC000111, 2002.

Bates, T. S., Charlson, R. J., and Gammon, R. H.: Evidence for the climatic role of marine biogenic sulphur, Nature, 329, 319-321, 1987.
Bates, T. S., Lamb, B. K., Guenther, A., Dignon, J., and Stoiber, R. E.: Sulfur emissions to the atmosphere from natural sources, J. Atmos. Chem., 14, 315-337, 1992.

Bates, T. S., Kiene, R. P., Wolfe, G. V., Matrai, P. A., Chavez, F. P., Buck, K. R., Blomquist, B. W., and Cuhel, R. L.: The cycling of sulfur in surface seawater of the northeastern Pacific, J. Geophys. Res., 99, 7835-7843, 1994.

Bates, T. S., Quinn, P. K., Covert, D. S., Coffman, D. J., Johnson, J. E., and Wiedensohler, A.: Aerosol physical properties and processes in the lower marine boundary layer: A comparison of shipboard sub-micron data from ACE-1 and ACE-2, Tellus 52B, 258-272, 2000.

Bell, T. G., Malin, G., McKee, C. M., and Liss, P. S.: A comparison of dimethylsulphide (DMS) data from the Atlantic Meridional Transect (AMT) programme with proposed algorithms for global surface DMS concentrations, Deep Sea Res. II, 53, 1720-1735, 2006.

Belviso, S., Bopp, L., Moulin, C., Orr, J. C., Anderson, T. R., Aumont, O., Chu, S., Elliott, S., Maltrud, M. E., and Simó, R.: Comparison of global climatological maps of sea surface dimethyl sulfide, Global Biogeochem. Cy., 18, GB3013, doi:10.1029/2003GB002193, 2004a.

Belviso, S., Moulin, C., Bopp, L., and Stefels, J.: Assessment of a global climatology of oceanic dimethylsulfide (DMS) concentrations based on SeaWiFS imagery (1998-2001), Canad. J. Fish. Aquat. Sci., 61, 804-816, doi:810.1139/f1104-1001., 2004b.

Belviso, S. and Caniaux, G.: A new assessment in North Atlantic waters of the relationship between DMS concentration and the upper mixed layer solar radiation dose, Global Biogeochem. Cy., 23, GB1014, doi:10.1029/2008GB003382, 2009.

Bigg, E. K. and Leck, C.: Properties of the aerosol over the central Arctic Ocean, J. Geophys. Res., 106, 32101-32109, 2001.

Bretherton, C. S., Uttal, T., Fairall, C. W., Yuter, S., Weller, R., Baumgardner, D., Comstock, K., and Wood, R.: The EPIC 2001 stratocumulus study, B. Am. Meteorol. Soc., 85, 967-977, 2004.

Brock, T. D.: Calculating solar-radiation for ecological studies, Ecol. Model., 14, 1-19, 1981.

Calleja, M. L., Duarte, C. M., Prairie, Y. T., Agustí, S., and Herndl, G. J.: Evidence for surface organic matter modulation of air-sea $\mathrm{CO}_{2}$ gas exchange, Biogeosciences, 6, 1105-1114, doi:10.5194/bg-6-1105-2009, 2009.

Charlson, R. J., Lovelock, J. E., Andreae, M. O., and Warren, S. G.: Oceanic phytoplankton, atmospheric sulphur, cloud albedo and climate, Nature, 326, 655-661, 1987.

Chu, S., Elliott, S., and Maltrud, M. E.: Global eddy permitting simulations of surface ocean nitrogen, iron, sulfur cycling, Chemosphere, 50, 223-235, 2003.

Claustre, H.: The trophic status of various oceanic provinces as revealed by phytoplankton pigment signatures, Limnol. Oceanogr., 39, 1206-1210, 1994.

Cronin, M. F., Bond, N. A., Fairall, C. W., and Weller, R. A.: Surface cloud forcing in the east Pacific Stratus Deck/Cold Tongue/ITCZ complex, J. Climate, 19, 392-409, 2006.

Dacey, J. W. H., Howse, F. A., Michaels, A. F., and Wakeham, S. G.: Temporal variability of dimethylsulfide and dimethylsulfoniopropionate in the Sargasso Sea, Deep Sea Res., 45, 20852104, 1998.

de Boyer Montegut, C., Madec, G., Fischer, A. S., Lazar, A., and Iudicone, D.: Mixed layer depth over the global ocean: An ex- 
amination of profile data and a profile-based climatology, J. Geophys. Res. C: Oceans, 109, 1-20, 2004.

Derevianko, G. J., Deutsch, C., and Hall, A.: On the relationship between ocean DMS and solar radiation, Geophys. Res. Lett., 36, L17606, doi:10.1029/2009GL039412, 2009.

Evans, C., Malin, G., Wilson, W. H., and Liss, P. S.: Infectious titres of Emiliania huxleyi virus 86 are reduced by exposure to millimolar dimethyl sulfide and acrylic acid, Limnol. Oceanogr., 51, 2468-2471, 2006.

Hefu, Y. and Kirst, G. O.: Effect of UV-radiation on DMSP content and DMS formation of Phaeocystis antartica, Polar Biol., 18, 402-409, 1997.

Herndl, G. J., Muller-Niklas, G., and Frick, J.: Major role of ultraviolet-B in controlling bacterioplankton growth in the surface layer of ocean, Nature, 361, 717-719, 1993.

Holm-Hansen, O., Lorenzen, C., Holmes, R., and Strickland, J.: Fluorometric determination of chlorophyll, ICES J. Mar. Sci., 30, 3-15, 1965.

Karsten, U., Kck, K., Vogt, C., and Kirst, G. O.: Dimethylsulfoniopropionate production in phototrophic organisms and its physiological function as a cryoprotectant, in: Biological and Environmental Chemistry of DMSP and Related Sulfonium Compounds, edited by: Kiene, R. P., Visscher, P. T., Keller, M. D., and Kirst, G. O., Plenum Press, New York, USA, 143-153, 1996.

Keller, M. D., Bellows, W. K., and Guillard, R. R. L.: Dimethyl sulphide production in marine phytoplankton, in: Biogenic sulfur in the environment, edited by: Saltzman, E. and Cooper, W. J., American Chemical Society, Washington DC, USA, 167-182, 1989.

Kettle, A. J. and Andreae, M. O.: Flux of dimethylsulfide from the oceans: A comparison of updated data sets and flux models, J. Geophys. Res., 105, 26793-26808, 2000.

Kettle, A. J., Andreae, M. O., Amouroux, D., Andreae, T. W., Bates, T. S., Berresheim, H., Bingemer, H., Boniforti, R., Curran, M. A. J., DiTullio, G. R., Helas, G., Jones, G. B., Keller, M. D., Kiene, R. P., Leck, C., Levasseur, M., Malin, G., Maspero, M., Matrai, P., McTaggart, A. R., Mihalopoulos, N., Nguyen, B. C., Novo, A., Putaud, J. P., Rapsomanikis, S., Roberts, G., Schebeske, G., Sharma, S., Simó, R., Staubes, R., Turner, S., and Uher, G.: A Global Database of Sea Surface Dimethylsulfide (DMS) Measurements and a Procedure to Predict Sea Surface DMS as a Function of Latitude, Longitude, and Month, Global Biogeochem. Cy., 13, 399-444, 1999.

Kiene, R. P. and Linn, L. J.: The fate of dissolved dimethylsulfoniopropionate (DMSP) in seawater: tracer studies using 35S-DMSP, Geochimica et Cosmochimica Acta, 64, 2797-2810, 2000.

Kirst, G. O.: Osmotic adjustment in phytoplankton and macroalgae, in: Biological and Environmental Chemistry of DMSP and Related Sulfonium Compounds, edited by: Kiene, R. P., Visscher, P. T., Keller, M. D., and Kirst, G. O., Plenum Press, New York, USA, 121-129, 1996.

Kniveton, D. R., Todd, M. C., Sciare, J., and Mihalopoulos, N.: The net effect of ultraviolet radiation on atmospheric dimethylsulphide over the Southern Indian Ocean, Philosoph. Trans. Roy. Soc. A, 363, 187-189, 2005.

Lee-Taylor, J. and Madronich, S.: Climatology of UV-A, UV-B, and Erythemal Radiation at the Earth's Surface, 1979-2000. Technical Note TN-474+STR, NCAR, Boulder, CO, USA, 2007.

Longhurst, A.: Seasonal cycles of pelagic production and consump- tion, Prog. Oceanogr., 36, 77-167, 1995.

Longhurst, A.: Ecological Geography of the Sea, 2e ed., Academic Press, San Diego, CA, USA, 2007.

Marín, V. H. and Delgado, L. E.: S-chlorophyll squirts in the Chilean coast: a SeaWiFS perspective, Gayana, 68, 381-384, doi:10.4067/S0717-65382004000300012, 2004.

Matrai, P. A. and Keller, M. D.: Dimethylsulfide in a large-scale coccolithophore bloom in the Gulf of Maine, Cont. Shelf Res., 13, 831-843, 1993.

McGillicuddy Jr., D. J., Anderson, L. A., Bates, N. R., Bibby, T., Buesseler, K. O., Carlson, C. A., Davis, C. S., Ewart, C., Falkowski, P. G., Goldthwait, S. A., Hansell, D. A., Jenkins, W. J., Johnson, R., Kosnyrev, V. K., Ledwell, J. R., Li, Q. P., Siegel, D. A., and Steinberg, D. K.: Eddy/Wind Interactions Stimulate Extraordinary Mid-Ocean Plankton Blooms, Science, 316, 1021-1026, doi:10.1126/science.1136256, 2007.

Miles, C. J., Bell, T. G., and Lenton, T. M.: Testing the relationship between the solar radiation dose and surface DMS concentrations using in situ data, Biogeosciences, 6, 1927-1934, doi:10.5194/bg-6-1927-2009, 2009.

Monterey, G. and Levitus, S.: Seasonal Variability of Mixed Layer Depth for the World Ocean, NOAA Atlas NESDIS 14, Washington, DC, USA, 1997.

Nightingale, P. D., Malin, G., Law, C. S., Watson, A. J., Liss, P. S., Liddicoat, M. I., Boutin, J., and Upstill-Goddard, R. C.: In situ evaluation of air-sea exchange parameterizations using novel conservative and volatile tracers, Global Biogeochem. Cy., 14, 373-387, 2000.

O’Dowd, C. D., Smith, M. H., Consterdine, I. E., and Lowe, J. A.: Marine aerosol, sea-salt, and the marine sulphur cycle: a short review, Atmos. Environ., 31, 73-80, 1997.

Parsons, T. R., Maita, Y., and Lalli, C. M.: A manual of chemical and biological methods for seawater analysis, Pergamon Press, Oxford, 1984.

Schlitzer, R.: Ocean Data View, available online at: http://odv.awi. de, 2010.

Serpetzoglou, E., Albrecht, B. A., Kollias, P., and Fairall, C. W.: Boundary Layer, Cloud, and Drizzle Variability in the Southeast Pacific Stratocumulus Regime, J. Climate, 21, 6191-6214, 2008.

Simó, R. and Pedros-Alio, C.: Role of vertical mixing in controlling the oceanic production of dimethyl sulphide, Nature, 402, 396399, 1999.

Simó, R. and Dachs, J.: Global ocean emission of dimethylsulfide predicted from biogeophysical data, Global Biogeochem. Cy., 16, 1078, doi:10.1029/2001GB001829, 2002.

Stefels, J.: Physiological aspects of the production and conversion of DMSP in marine algae and higher plants, J. Sea Res., 43, 183 197, 2000.

Stefels, J. and van Boekel, W. H. M.: Production of DMS from dissolved DMSP in axenic cultures of the marine phytoplankton species Phaeocystis sp., Marine Ecol. Prog. Series, 97, 11-18, 1993.

Stefels, J., Steinke, M., Turner, S., Malin, G., and Belviso, S.: Environmental constraints on the production and removal of the climatically active gas dimethylsulphide (DMS) and implications for ecosystem modelling, Biogeochemistry, 83, 245-275, 2007.

Steinke, M., Malin, G., and Liss, P. S.: Trophic interactions in the sea: An ecological role for climate relevant volatiles?, J. Phycol., 38, 630-638, 2002. 
Stevens, B., Vali, G., Comstock, K., Wood, R., Van Zanten, M. C., Austin, P. H., Bretherton, C. S., and Lenschow, D. H.: Pockets of Open Cells and Drizzle in Marine Stratocumulus, B. Am. Meteorol. Soc., 86, 51-57, 2005.

Sunda, W., Kieber, D. J., Kiene, R. P., and Huntsman, S.: An antioxidant function for DMSP and DMS in marine algae, Nature, 418, 317-320, 2002.

Toole, D. A. and Siegel, D. A.: Light-driven cycling of dimethylsulfide (DMS) in the Sargasso Sea: closing the loop, Geophys. Res. Lett., 31, L09308, doi:10.1029/2004GL019581, 2004.

Toole, D. A., Kieber, D. J., Kiene, R. P., Siegel, D. A., and Nelson, N. B.: Photolysis and the dimethylsulfide (DMS) summer paradox in the Sargasso Sea, Limnol. Oceanogr., 48, 1088-1100, 2003.
Vallina, S. M. and Simó, R.: Strong relationship between DMS and the solar radiation dose over the global surface ocean, Science, 315, 506-508, 2007.

Wolfe, G. V., Steinke, M., and Kirst, G. O.: Grazing-activated chemical defence in a unicellular marine alga, Nature, 387, 894896, 1997.

Yang, M., Blomquist, B. W., and Huebert, B. J.: Constraining the concentration of the hydroxyl radical in a stratocumulus topped marine boundary layer from sea-to-air eddy covariance flux measurements of dimethylsulfide, Atmos. Chem. Phys., 9, 92259236, doi:10.5194/acp-9-9225-2009, 2009. 